\section{LOS MECANISMOS DE LA DEMOCRACIA EN EL PENSAMIENTO POLÍTICO DE ALEXIS DE TOCQUEVILLE}

\author{
Tomás Gil \\ TU Berlin
}

\begin{abstract}
The article intends to reconstruct the functionalist conception of Tocqueville's democracy, a concept that focus on the beneficial effects of the democracy by describing some of the mechanisms of its practical way of operating.
\end{abstract}

KEY WORDS: Tocqueville; democracy; effects of the equality; political freedom; civil society; religious experience.

Mi interés por el pensamiento político de Alexis de Tocqueville es ante todo un interés metodológico. Pienso que de Tocqueville podemos aprender en qué consiste la labor del científico social: lo que puede llegar a conseguir y cómo lo consigue. No ignoro en absoluto las contradicciones que podemos encontrar en sus obras. Sin embargo, aprecio cómo desarrolla ciertas explicaciones de fenómenos sociales, evitando la utilización de conceptos abstractos y recurriendo a mecanismos concretos que los causaron.

Karl Popper afirmó en su libro "The Poverty of Historicism" que en el terreno de la historia no hay leyes que nos permitan predecir con seguridad lo que va a suceder, como (de acuerdo con Popper) así lo pretendieron tanto Hegel como Marx. Popper lleva razón al afirmar que el proceso histórico no está determinado de antemano. Pero eso no quiere decir en absoluto, como Popper proclama, que no haya regularidades o leyes en el mismo. Es verdad, como afirma Popper, que no podemos anticipar lo que en el futuro pasará. Mas esto no quiere decir que no seamos capaces de explicar lo que ha pasado, recurriendo a cadenas causales que lo han hecho posible. Lo que pasará, los acontecimientos futuros, los "futura" no existen ya y ahora, separados de nuestro saber, en algún lugar imaginario que se va haciendo poco a poco realidad. Una tal visión es errónea. Pero, cuando los acontecimientos futuros hayan sucedido, sí podemos explicarlos en argumentaciones

\section{THE MECHANISMS OF THE DEMOCRACY IN THE ALEXIS DE TOCQUEVILLE POLITICAL THINKING}

RESUMEN: El artículo se propone reconstruir la concepción funcionalista de la democracia de Tocqueville, una concepción que se concentra en los efectos benéficos de la democracia, describiendo algunos de los mecanismos de su funcionamiento práctico.

PALABRAS CLAVE: Tocqueville; democracia; efectos de la igualdad; libertad política; sociedad civil; experiencia religiosa.

que indican sus causas reales. Por eso, no nos tenemos que contentar en el terreno de lo social, lo político y lo económico con simples narraciones de lo sucedido, sino que podemos dar explicaciones ex post fuertes de lo acontecido. Para esas explicaciones no nos valen las leyes o las regularidades generales, debido a su intrínseca ambigüedad. Las así denominadas leyes, que por supuesto existen, son demasiado vagas, generales o abstractas. No sirven para explicar nada específico. Para ello necesitamos algo más concreto: mecanismos causales. Existe, por poner un ejemplo, la "ley de la demanda", de acuerdo con la cual la subida de los precios lleva a un descenso del consumo. Sirviéndonos de esta ley o regularidad práctica no podremos nunca explicar ningún comportamiento concreto. Necesitamos más informaciones, más datos que nos permitan elaborar una explicación satisfactoria. Pues puede siempre darse el caso de una subida de precios acompañada de un cierto aumento del consumo, como bien lo prevé el efecto "Veblen" de un "conspicuous consumption". Formulado de otra manera, la subida de los precios puede generar un mayor o menor consumo, por lo que la utilización de una ley tan abstracta no sirve para mucho a la hora de explicar comportamientos concretos.

Sólo conseguiremos explicaciones satisfactorias sirviéndonos de mecanismos o de cadenas causales pertinentes que generen realmente los fenómenos que intentamos explicar. 
Cómo se lleva a cabo esta labor de explicación ex post nos lo muestra Tocqueville en su obras sobre la democracia en América y sobre la Revolución Francesa. Es por eso por lo que un estudio de su pensamiento se convierte en algo inevitable para todo interesado en la metodología de las ciencias sociales. Su tratamiento de la democracia moderna me parece además muy digno de consideración, pues, a diferencia de otros filósofos sociales y políticos como Jürgen Habermas, Tocqueville no está interesado en una justificación moral de la democracia, sino en un estudio de sus distintas funcionalidades. A su procedimiento funcionalista, fenomenólogico y comparativo dedico a continuación mi atención en un primer apartado, antes de considerar en una segunda parte distintos mecanismos de la democracia moderna, que tan magistralmente Tocqueville supo analizar.

\section{AnÁlisis comparativo}

Alexis de Tocqueville es, tal y como lo admiten entre otros muchos autores André Jardin, Raymond Boudon y Laurence Guellec, un excelente escritor con un estilo brillante. Mas tras ese brillante estilista hay un científico social que es el que aquí interesa.

Tocqueville describe cómo en la sociedad moderna "democrática" se va degradando la cultura tradicional, se aumentan los derechos individuales, se suavizan las costumbres y las formas de represión y se llega a una religiosidad más pragmática que dogmática. Sus descripciones son siempre comparativas. Mira desde fuera para comprender lo que pasa dentro de una cierta colectividad, consiguiendo un conocimiento comparado que contrasta siempre dos cosas distintas, es decir, que utiliza dos fenómenos o entidades diferentes como la sociedad aristocrática y la sociedad democrática, América y Francia, el sur y el norte de los Estados Unidos. A este pensamiento comparativo le ha dado James T. Schleifer el nombre de "thinking in pairs" (Welch, 123). A través de los detalles, que son descritos magistralmente, llega Tocqueville a las totalidades que le interesan. Ofrece pruebas y demostraciones "en negativo" ("reverse proofs"). Sus exposiciones asumen el carácter de demostraciones silogísticas encuadradas en esquemas de argumentación del tipo "dado que..., entonces o por consiguiente". Sin embargo, esto no es todo lo que encontramos en sus textos. En ellos encontramos "explicaciones" de los fenómenos tratados, de los distintos hechos sociales, políticos y culturales que se presentan.

Tales explicaciones presuponen que lo que se trata de explicar, el "explanandum", se vea individualizado. Hay, de hecho, cosas inexplicables en un sentido estricto y esto debido a su complejidad. Por ejemplo, sería absurdo pretender explicar en su totalidad la Revolución Francesa o la biografía de una cierta persona. Por el contrario, sí que se pueden explicar ciertos hechos individuales, no dando razones especulativas, abstractas o metafísicas, que recurrirían a ideas o entidades como el "genio de los pueblos" (por dar el ejemplo de la entidad utilizada por Guizot a quien el mismo Tocqueville critica debido a sus especulaciones metafísicas), sino formulando hipótesis falsables. Esto es precisamente lo que Tocqueville hace o pretende hacer.

Tocqueville quiere explicar ciertos aspectos de la experiencia religiosa en tanto que fenómeno social y cultural. Quiere además explicar la preponderancia de la orientación racional en ciertas sociedades y analiza las consecuencias de un Estado fuerte y centralizado. Para ello se sirve de construcciones condicionales que integran modelos teóricos y que presentan la forma "si $A$, entonces B". Tales construcciones condicionales son el esqueleto, la estructura formal de distintos mecanismos existentes que, en tanto que cadenas causales, generan efectos reales. Un tal mecanismo sería la conocida "frustración relativa", mecanismo del que se sirvió James Davies para elaborar su "curva de la revolución" y que se podría formular de la siguiente manera: "Cuanto más mejoran las condiciones objetivas, más aumenta la insatisfacción y la disposición a protestar o incluso a llevar a cabo una revolución" (Zapf, 399ss. y Boudon, 129s.). A tales mecanismos recurre Tocqueville en sus explicaciones causales. En "L'ancien régime et la Révolution" analiza Tocqueville magistralmente el mecanismo de la "frustración relativa" en el capítulo cuarto del tercer libro que lleva por título: "Que le règne de Louis XVI a été l'époque la plus prospère de l'ancienne monarchie, et comment cette prosperité même hâta la Révolution." En la página 276 escribe: "A mesure que se développe en France la prospérité que je viens de décrire, les esprits paraissent cependant plus mal assis et plus inquiets; le mécontentement public s'aigrit; la haine contre toutes les institutions anciennes va croissant. La nation marche visiblement vers une révolution." Es por eso por lo que puede resumir Toc- 
queville: "de telle sorte qu'on dirait que les Français ont trouvé leur position d'autant plus insupportable qu'elle devenait meilleure" (Tocqueville, 1967, 277). Aquí tenemos el mecanismo de la frustración relativa: cuanto más ligera la carga, menos tolerable se hace; cuanto más llevadero el yugo, más insoportable es su misma existencia (TocqueviIle, 1967, 85, 87, 94 y 97).

\section{LOS MECANISMOS DE LA DEMOCRACIA}

En los escritos de Tocqueville encontramos muchas contradicciones. Jon Elster ha hecho una lista de esas contradicciones clasificándolas tipológicamente (Elster, 112ss.). Hay, en efecto: 1) contradicciones entre el primer y el segundo volumen de la "Democracia en América"; 2) contradicciones que se deben a la confusión entre aquello que es democrático y aquello que es típicamente americano; 3 ) contradicciones del tipo: "A es la causa de B y C" y "B y C no son compatibles"; 4) contradicciones del tipo: "A es la causa de C", "B es la causa de C" y "A y B son el efecto de $D^{\prime \prime}$; 5) contradicciones del tipo "A es la causa de B" y "B es la causa de $A "$; 6) contradicciones manifiestas o burdas.

A continuación me intereso, a diferencia de Elster, por las explicaciones logradas y no tanto por las contradicciones existentes. De estas explicaciones más o menos logradas trata lo que a continuación sigue. Son explicaciones que conciernen a cuatro temas muy importantes del pensamiento político de Tocqueville. Me refiero a los temas de la "dinámica de la igualdad", la "libertad política", la "sociedad civil" y la "experiencia religiosa".

\subsection{La dinámica y los efectos de la igualdad}

Alexis de Tocqueville no es un amante de la igualdad, mas se da cuenta de que la igualdad en tanto que proceso que lleva a que los hombres sean cada vez más iguales es algo inevitable en la modernidad. Es por eso por lo que estudia su dinámica y sus mecanismos, en concreto: los factores que la generan, sus clases y tipos, las consecuencias de la igualdad, los posibles peligros que trae consigo y posibles antídotos.

Entre los factores que la generan, Tocqueville dedica especial atención: a las condiciones de vida cada vez más iguales para todos en el mundo moderno, al cristianismo en su versión protestante, a las armas de fuego, la imprenta y la igualdad de los inmigrantes colonos en Norteamérica.

Concerniendo a los tipos y clases de igualdad, Tocqueville distingue la igualdad política, la social y la cultural.

Respecto al tema de las consecuencias de la igualdad, Tocqueville defiende las siguientes tesis que ilustra con una cantidad considerable de ejemplos: la igualdad promueve el espíritu crítico y la incredulidad; promueve el individualismo (poniendo entre otras cosas en peligro a la institución de la familia debido a la movilidad geográfica y social que siempre lo acompañan); favorece la producción de obras culturales sencillas y prácticas; favorece la creación y expansión de modas y tendencias pasajeras; trae consigo un cierto tipo de historiografía (en la que los grandes hombres y los héroes pierden su antigua importancia y colectividades y grupos se convierten en protagonistas); lleva a la pérdida de importancia de un cierto tipo de honor (el honor aristocrático) y favorece la abolición de la esclavitud.

No todas las consecuencias de la igualdad son neutras o positivas. Hay algunas claramente negativas que Tocqueville considera como peligros de la igualdad y a las que dedica especial atención: la victoria de la mediocridad y del promedio; la tiranía de la mayoría y la amenaza a la libertad que la igualdad representa.

Tocqueville piensa, por otra parte, que hay una serie de antídotos contra estos males y peligros de la igualdad que son, ellos mismos, recursos propios de la igualdad democrática. Se interesa especialmente por dos. El primero es el federalismo y sus instituciones comunales. El segundo es la constitución y la estructura del poder legal, lo que Tocqueville denomina el "espíritu legalista", es decir, la manera de funcionar del sistema legal con sus diferentes instrumentos (por ejemplo, los jurados). Como experto en leyes, Tocqueville caracteriza magistralmente el sistema legal americano que funciona siempre como árbitro, tratando sobre casos concretos (y no sobre principios) y siendo un sistema a activar 0 al que hay que recurrir para que entre en acción (Tocqueville, 1961, l, 164ss. y 390ss.)

\subsection{La libertad política}

Para Tocqueville la libertad política es una serie o conjunto de derechos dentro de un sistema legal (el derecho de

ARBOR Vol. 187750 julio-agosto [2011] 671-675 ISSN: 0210-1963 
libre prensa, de asociación y de religión) y la práctica o la cultura concreta de esos derechos, es decir, un conjunto de actividades.

Al tratar el tema de la libertad, Tocqueville habla de las consecuencias de un gobierno libre, de la libertad democrática comparada con la libertad aristocrática y de la libertad como un bien intrínseco. Pero más que nada, lo que realmente le interesa a Tocqueville son los peligros que surgen en una sociedad democrática igualitaria para la libertad. Hablando de peligros distingue: los peligros pequeños o amenazas y los peligros reales o grandes de la libertad (a los que se refiere con los conceptos de "despotismo" o "tiranía", conceptos que utiliza como sinónimos). Cinco clases de verdaderos peligros hay para la libertad, de acuerdo con Tocqueville, en las sociedades democráticas modernas: 1) el "despotismo legislativo", es decir, el despotismo del poder legislativo, del parlamento o asamblea elegida por los ciudadanos que elabora cada vez más leyes; 2) la "tiranía de la mayoría" y de la "opinión pública" que se impone subrepticiamente y sin violencia; 3 ) el gobierno despótico o la tiranía de posibles Césares; 4) el "despotismo administrativo" que se aprovecha de la apatía política, del individualismo y del materialismo existentes en las sociedades democráticas; 5) el "despotismo imperial" y "militar". En un pasaje bien significativo y que por eso cito en su totalidad, formula Tocqueville: "je vois une foule innombrable d'hommes semblables et égaux qui tournent sans repos sur eux-mêmes pour se procurer de petits et vulgaires plaisirs, dont ils emplissent leur âme. Chacun d'eux, retiré à l'écart, est comme étranger à la destinée de tous les autres... Audessus de ceux-là s'élève un pouvoir immense et tutélaire, qui se charge seul d'assurer leur jouissance et de veiller sur leur sort. II est absolu, détaillé, régulier, prévoyant et doux" (Tocqueville, 1961, II, 434). Así describe Tocqueville la estructura de posibles despotismos que surgen dentro de sociedades igualitarias, en las que los individuos viven aislados los unos de los otros, desinteresados de los asuntos comunes, entregados a la satisfacción de sus deseos particulares y un poder político "absolu, détaillé, régulier, prévoyant et doux" se hace omnipresente.

\subsection{La sociedad civil}

No hay nada tan fundamental para las democracias modernas como la sociedad civil. Ésta es su rasgo más característico.
La sociedad civil es algo intermedio entre los individuos y el estado, es lo "intermediario" por excelencia, en donde florece el sentido de la ciudadanía y de la vida pública a través de distintas prácticas de asociacionismo. No es un reino aislado, una esfera separada de otras esferas, sino una serie de organizaciones mediadoras, de costumbres y de hábitos. La sociedad civil tiene "componentes" y "recursos".

Los "componentes" que la integran son: la separación de iglesia y estado; una prensa libre; la estructura federal de gobierno; una serie de asociaciones políticas permanentes; las asociaciones civiles (no políticas); diversas reuniones municipales o a nivel de las distintas ciudades (los asi llamados "town meetings").

El "espiritu de asociacionismo" y sus distintas maneras de funcionar en concreto son los mejores "recursos" que tiene la sociedad civil: la actividad desarrollada por las asociaciones políticas, caritativas, educacionales, religiosas, de vecindad y profesionales que la integran. En todas estas actividades de las asociaciones que constituyen la sociedad civil se forman, crean y cultivan "hábitos y costumbres" democráticos que contribuyen a una vida social y profesional fuerte y viva. Es precisamente esa fuerza y vivacidad de las profesiones y de la vida social en general la que configura, según Tocqueville, el estado moral e intelectual de un pueblo, el recurso principal de la sociedad civil que puede servir de antídoto a posibles males democráticos.

Tocqueville resalta en especial el federalismo de las instituciones comunales y el espíritu legalista (junto con la institución jurídica de los jurados) como tendencias democráticas intermedias entre el individuo aislado y el Estado o la nación.

La concepción de la sociedad civil de Tocqueville es una concepción política de la sociedad civil y de la libertad. En su centro se halla la libertad política que se vería amenazada por un Estado democrático totalitario. Como formula Dana Villa en su artículo "Tocqueville and Civil Society", el concepto de Tocqueville de la sociedad civil es "political at its very core" (Welch, 235s.) La sociedad civil es para Tocqueville aquello que hace posible una vida pública y política. Ésta sería su fruto y, al mismo tiempo, su condición de posibilidad. 


\subsection{La experiencia religiosa}

El fenómeno religioso se configura de una manera específica en los Estados Unidos. Encontramos aquí una religiosidad que es capaz de autolimitarse y que no está dominada por dogmas (creencias doctrinarias) o autoridades religiosas. La experiencia personal cuenta más que la así denominada fides quae (el contenido dogmático de la fe). La experiencia personal es compatible además con los intereses privados de los individuos y con la dinámica de una economía en desarrollo de tal forma que se da una compatibilidad de principio entre un utilitarismo tanto privado como colectivo y la religiosidad vivencial, nodogmática. Finalmente, se da en los Estados Unidos una difícil dialéctica entre inmanentismo y su compensación espiritualista, a veces fundamentalista exaltada, que, ante la complejidad de muchas cosas en el mundo moderno, opta por respuestas simples y sencillas. Tocqueville se interesa por estos rasgos característicos de la religiosidad en América que compara con el catolicismo típico de sociedades aristocráticas como la sociedad francesa prerrevolucionaria. En términos generales, analiza los efectos de la religión y constata toda una serie de funciones, en especial, de la religiosidad en América. Entre sus efectos más destacados, resalta Tocqueville: su funcionalidad y utilidad general; la manera como compromete, ata y subyuga a la inteligencia; cómo se concentra en algunas creencias fundamentales, dejando gran libertad en cuanto a las formas externas del culto; cómo apoya a las opiniones generalizadas; cómo no desprecia los bienes materiales y la importancia del presente y de la mentalidad laboral; cómo moraliza la democracia y, lo más importante de todo, cómo generaliza la idea de la inmortalidad del alma, una idea que en palabras de Tocqueville contribuye sustancialmente a la grandeza del hombre (Tocqueville, 1961, II, 38, 40, 45s. y 200ss.).
Recibido: 17 de diciembre de 2009

Aceptado: 17 de febrero de 2010

\section{BIBLIOGRAFÍA}

Boudon, Raymond (2005): Tocqueville aujourd'hui, Paris, Odile Jacob.

Elster, Jon (1993): Political Psychology, Cambridge, Cambridge University Press.

Hereth, Michael (1991): Tocqueville zur Einführung, Hamburgo, Junius.

Jardin, André (1984): Alexis de Tocqueville 1805-1859, Paris, Hachette.

Manent, Pierre (1982): Tocqueville et la nature de la démocratie, Paris, Julliard.
Popper, Karl R. (1976): The Poverty of Historicism, Londres, Routledge.

Tocqueville, Alexis de (1961): De la démocratie en Amérique I y II, Paris, Gallimard.

Tocqueville, Alexis de (1967): L'ancien régime et la Révolution, Paris, Gallimard.

Welch, Cheryl B. (Ed.) (2006): The Cambridge Companion to Tocqueville, Cambridge, Cambridge University Press.

Zapf, Wolfgang (Ed.) ( $\left.{ }^{4} 1979\right)$ : Theorien des sozialen Wandels, Königstein/Ts., Athenäum. 